\section{Referendum stalls Japanese nuclear power strategy}

\section{David Cyranoski, Tokyo}

Japan's plans to adapt its nuclear power programme to burn recycled nuclear fuel have been sent reeling by a referendum in a small town on the country's west coast.

On 27 May, the residents of Kariwa in Niigata - a community of just over 5,000 people - rejected by 1,925 votes to 1,533 the introduction of mixed oxide (MOX) fuel at the nearby Kashiwazaki-Kariwa nuclear power plant.

MOX fuel mixes recycled plutonium oxide, extracted from spent nuclear fuel, with uranium oxide. Under Japan's plan, one-third of the country's 51 light watercooled nuclear power stations would start to burn MOX by 2010.

Although the Kariwa referendum is not legally binding, government officials, including Prime Minister Jun'ichiro Koizumi, have said they recognize the need to get the backing of local people before proceeding with the plans.

Critics of nuclear-fuel reprocessing say that the vote could have global ramifications, by dimming the prospects that Japan will become a major user of the technology. "The Kariwa referendum could be the mouse that roared," says Paul Leventhal of the Washington-based Nuclear Control Institute.

But both industry and government officials said after the referendum that the plan to burn MOX fuel at the power station will still proceed, albeit after some delay.

During the Kariwa referendum campaign, opponents of the plan claimed that MOX was more radioactive than existing fuel. They also said that because MOX contains plutonium, it could be adapted for use in nuclear weapons. "The Japanese government has never levelled with the Japanese people about these issues," says Leventhal.

In addition, critics claim that there is no need to reprocess spent fuel into MOX, given the plentiful supply of cheap uranium, and that reprocessing is being pursued largely as a means of deferring the problem of disposing of nuclear fuel. "As soon at they throw out the idea of recycling the spent fuel, they have to say what they would do with it,"says Aileen Smith of Green Action, a Kyoto-based environmental group.

"If the MOX fuel cannot be used at the reactors, we will have no place to put it," admits one government official responsible for nuclear-energy policy. The official adds that there was "absolutely no chance" that Japan would pay Russia to store spent nuclear fuel (see Nature 411, 401;2001).

The idea of storing spent fuel rather than reprocessing it is taboo in government and

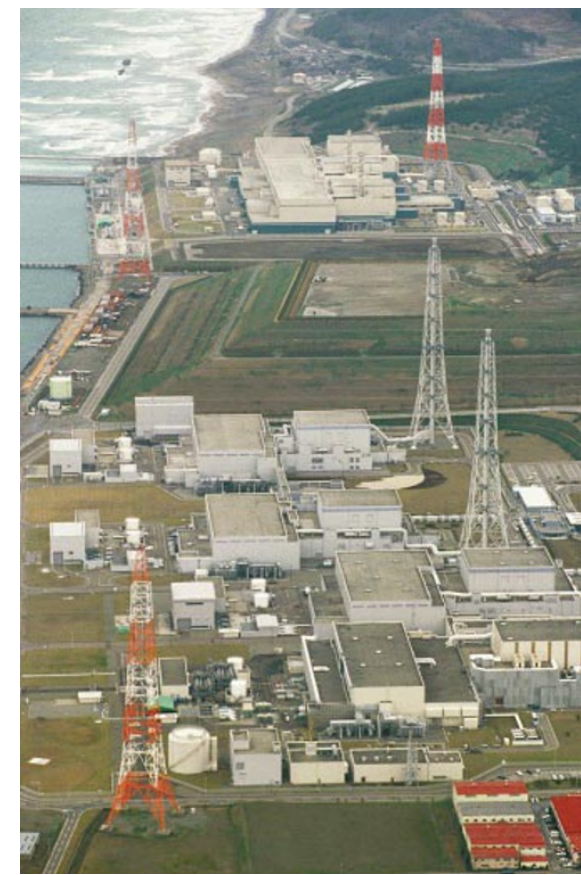

Voted out: locals have vetoed the use of recycled fuel at the Kashiwazaki-Kariwa nuclear plant.

industry circles, as there are no plans to build a long-term storage repository. Japan is instead investing more than $¥ 2$ trillion (US $\$ 17$ billion) in a reprocessing plant being built at Rokkasho, Aomori.

Electric companies that plan to burn MOX in Japan can only do so with the agreement of the regional governor, and such agreements have been reached with the governors of Fukui, Fukushima and Niigata.

But the discovery of falsified inspection data for a shipment of MOX fuel from Britain to Fukui put that region's project on hold. That scandal, together with accidents such as that at Tokai in 1999 (see Nature 401, 736; 1999), led the governor of Fukushima to ask for a year's delay on its MOX initiative. Now the Kariwa referendum looks set to delay the introduction of MOX in Niigata by a similar length of time.

Government and industry officials declined to say what would happen if the introduction of MOX is opposed at other power stations. One said that supporters of the plan will now embark on a programme aimed at "gaining the understanding of the people" concerning the safety of plutonium.

The United States abandoned nuclearfuel reprocessing in the 1970s, but other countries have continued to pursue it, and MOX fuel is used to generate power in several countries, including France, Germany and India. In Japan, it has been burned in research reactors, but not in power plants.

\section{Airborne telescope delayed as plane is made ready}

Tony Reichhardt, Washington

The first flight of a long-awaited airborne telescope developed by German and US scientists will take place two years later than planned, NASA officials have admitted. Take-off is now scheduled for late 2004 or early 2005.

The Stratospheric Observatory for Infrared Astronomy (SOFIA) was conceived as a follow-on to the Kuiper Airborne Observatory, which ended a productive 20 -year career in 1995 . The \$500-million project will use a Germanbuilt telescope the same size as the Hubble space telescope ( 2.5 metres in diameter) mounted in a converted Boeing 747.

The aircraft will fly three or four times a week from NASA's Ames Research Center in California, with a planned lifetime of 20 years. Cruising at altitudes of around 12,500 metres, above almost all of the infrared-absorbing water vapour in the atmosphere, SOFIA will study star and planet formation as well as the interstellar medium.

But modifying the airplane, which can stay aloft longer than a conventional 747 , has needed more manpower and money than the company doing the job Raytheon Aircraft Integration Systems in Waco, Texas — had bargained for. Faced with projected cost overruns of tens of millions of dollars, NASA has decided to delay the first flight by two years.

"We're not particularly happy about it," says Ken Ledbetter, director of the Flight Programs Division at NASA's Office of Space Science. But for an agency that is struggling to complete a series of missions started in the 1990s, it was the best available option. NASA science chief Ed Weiler even told a recent meeting of the National Research Council's Space Science Board that, were it not for the German involvement, he would have considered cancelling the project. http://sofia.arc.nasa.gov

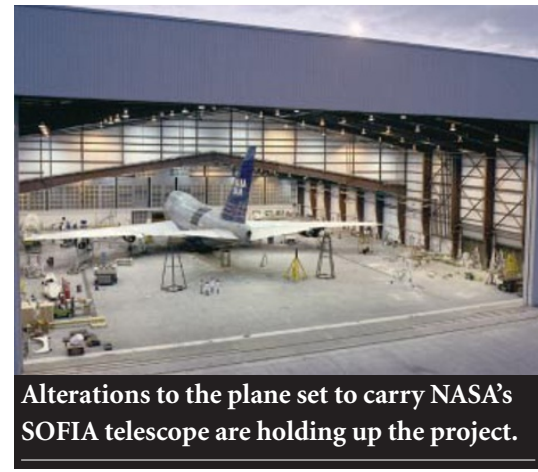

